\title{
Kaiser Julians Gottesverehrung im Kontext der Spätantike
}

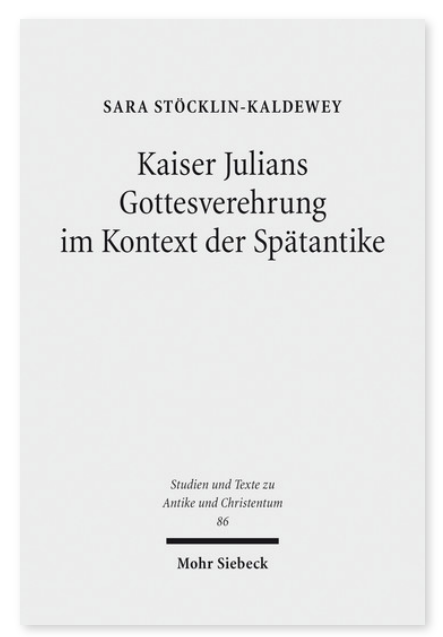

2014. XII, 456 Seiten. STAC 86

ISBN 978-3-16-153247-4

DOI 10.1628/978-3-16-153247-4

eBook PDF 114,00€

ISBN 978-3-16-153246-7

fadengeheftete Broschur 114,00€
Die hohe Relevanz der Götter- und Glaubenswelt in den Schriften Julians ist unübersehbar. Seine kaiserliche Stellung und Biographie haben dem vielfach artikulierten religiösen Gedankengut seit jeher Beachtung verschafft, denn sie machen Julian zu einer Schlüsselfigur für das Verständnis der religiösen Kultur der Spätantike. In einer systematischen Analyse von Julians Gesamtwerk untersucht Sara Stöcklin-Kaldewey die Vorstellungen, die der Frömmigkeit des Kaisers zugrunde liegen, und erörtert ihre Kohärenz, Begründungen und Konsequenzen. Dabei werden wiederkehrende Motive und Problemstellungen sichtbar, anhand derer eine Verortung auf der geistigen Landkarte der Spätantike vorgenommen wird. Vielfach erweisen sie sich als repräsentativ für die religiösen Diskurse der Zeit, für die großen Fragen, mit denen sich christliche Denker, Philosophen und Vertreter der paganen Bildungselite auseinandersetzen.

Sara Stöcklin-Kaldewey Geboren 1981; 2002-08 Studium der Philosophie und Theologie an der Universität Basel; 2009-13 Wissenschaftliche Mitarbeiterin am Lehrstuhl für Kirchengeschichte an der Universität Basel; 2013 Promotion; derzeit Mitarbeiterin Kommunikation bei der Heilsarmee Schweiz in Bern.
Jetzt bestellen:

https://mohrsiebeck.com/buch/kaiser-julians-gottesverehrung-im-kontext-der-spaetantike-9783161532474?no_cache=1 order@mohrsiebeck.com

Telefon: +49 (0)7071-923-17

Telefax: $+49(0) 7071-51104$ 